\title{
MENSUSMONITOR - Algorithm implementation for detecting live load events and assessment of structural effects on bridges
}

\author{
H. Sousa \& A. Henriques \& J. Figueiras \\ LABEST, Faculty of Engineering, University of Porto, Porto, Portugal \\ B. Costa \\ LABEST, Faculty of Engineering, University of Beira Interior, Covilhã, Portugal
}

\begin{abstract}
The handling and treatment of data from automatic monitoring systems installed in civil infrastructures is by itself a hard and time consuming task in the search of structural behavior knowledge. This paper presents the implementation of an algorithm for detecting live load events and assessment of structural effects on monitored bridges. The events detection algorithm offer a set of results in form of histograms events that characterize several variables distributions like the number of events detected, the amplitudes of observed parameters, or even the level of load applied to the structure. The proposed algorithm is implemented in the MENSUSMONITOR - software specifically devoted to the structural health monitoring. Grounded in the know-how gathered by the research unit FEUP-LABEST in the recent years, MENSUSMONITOR proposes to give faster and efficient answers to the processing and interpretation of records collected by the structural monitoring systems deployed on bridges.
\end{abstract}

\section{INTRODUCTION}

Nowadays, Structural Health Monitoring (SHM) is a subject of major interest in the Civil Infrastructures domain. The monitoring systems used in this domain are a powerful tool to verify the structures performance conformity with the advantage to give a valuable database to study in more detail the real behavior of the monitored structures (Sousa et al., 2008a). The most recent monitoring systems allow, in an automatic as well programmable mode, the observation and register of a set of parameters. This is possible by predefining reading procedures that are interpreted by the acquisition systems resulting in a database with the respective sensors readings. The size of those databases can quickly reach considerable dimensions. Considering the flexibility of the current monitoring systems used in civil infrastructures, the readings sample rate can go from $0.00001 \mathrm{~Hz}$ to $200 \mathrm{~Hz}$, in depending of the sensor type and/or of the respective acquisition system.

The long-term observation of concrete structures is mainly made by following the structure response to environmental actions and the delay effects of the concrete time dependent behavior, such as shrinkage and creep, with influence in the stress redistribution. For this case the sensors sampling rate is low, typical in the order of 1 sample per hour, and by consequence the volume of data is more easily manageable. However the long-term observation of metallic structures is different, since the dynamic response is crucial to evaluate the fatigue response of these flexible structures. For these structures, higher sampling rates are required, typically in the order of $200 \mathrm{~Hz}$, and the data management in these cases is more demanding. For both cases, the monitoring systems provide a database with great potentialities to evaluate the structural safety. But to have the desired answers in useful time, those databases must be consulted and analyzed with specific tools to extract the desired knowledge.

Furthermore, although the monitoring systems deployed on bridges aim to help both the structural integrity assessment and the management of maintenance/repair operations of large groups of structures, they can also be utilized to characterize the crossing traffic, if properly designed for it. As the bridge is equipped with a kit of sensors, and assuming its behavior remains linear elastic under normal operation conditions, the whole set can act as a balance and therefore measure traffic characteristics. This concept is known as bridge weigh-in-motion, commonly identified with the acronym B-WIM (Karoumi et al., 2005).

\section{MOTIVATION}

Considering the specifics of the SHM and the huge size of the databases derived by these monitoring systems, the authors point out the need for specific tools to improve in the treatment and interpretation 
of experimental results obtained in materials and structures of Civil Engineering. This reflection results from the experience acquired in the last years by FEUP-LABEST, a R\&D unit of the Faculty of Engineering - University of Porto. In this R\&D unit a group of researchers have been developing methodologies and tools aiming the implementation of the structural monitoring as a practical tool to support the structures safety evaluation, thus assuring a valid path towards a better comprehension of civil infrastructures real behavior. The problems discussion and their possible resolutions were the basis to create a common platform - MENSUSMONITOR.

The database consulting with the intention to extract a superior knowledge is a hard task, with significant time consuming, if no specific numerical tools are used. The potential knowledge given by the monitoring systems is high, but it is also important to reach that knowledge in real time for an effective management and surveillance of civil infrastructures (Sousa et al., 2008a).

\section{MENSUSMONITOR - THE APPLICATION TOOL}

MENSUSMONITOR is a specific application guided to the SHM cause, whose functionalities are intended to give useful help in the consulting, treatment and knowledge extraction from the collected data. Its mainframe is implemented in LabVIEW code (Beyon, 2001), with the attachment of a set of modules that can be developed in the same language code of the mainframe or in $\mathrm{C}++$ or MATLAB (Sousa et al., 2008a, b). Regarding its conception, MENSUSMONITOR is an application that have a main program that manage: (i) the input of data; (ii) the functioning of all numerical tools that transform that input data in other relevant information, and; (iii) the output data in form of data files that can be text files, graph images or summaries html pages. All these modules are dependent between them in a sequential manner but independent in what concerns to the source code (Sousa et al., 2008b). At the present, MENSUSMONITOR offer a set of numerical tools which are highlighted: (i) "mensus_samplingrate_change": readings sample reduction or increasing of an experimental result; (ii) "mensus_filter": data filter by using a filter library; (iii) "mensus_fitting": curve fitting of the theoretical expression of Eurocode 2 (Bebby, 2005) to experimental results; (iv) "mensus_correlation": identification of correlations between two experimental results and the corresponding correlation equation (Sousa et al., 2008b).
MENSUSMONITOR has a user guide to help the user in its use, namely in the correct use of the numerical tools. This was one of the noble aspects in the development of the MENSUSMONITOR, because compromised the numerical tools developers to think in the user perspective beyond the programmer perspective. Figure 1 illustrates the functional structure of MENSUSMONITOR.

To extract useful information from databases created by monitoring systems that acquire with high sampling rates, a new numerical tool was implemented and attached to the MENSUSMONITOR. The collected data with those high frequencies allow to characterize the dynamic behavior of the monitored structure, and identifies also the actions applied to the structure, namely live loads. An appropriate selection of the sensors positioning, as well as the sensors type, gives the possibility to have a weight balance that identifies traffic events which occur in the monitored structure. The adopted designation for the numerical tool was "mensus_traffic" considering the relevance that this tool has for the traffic characterization on the monitored structure.

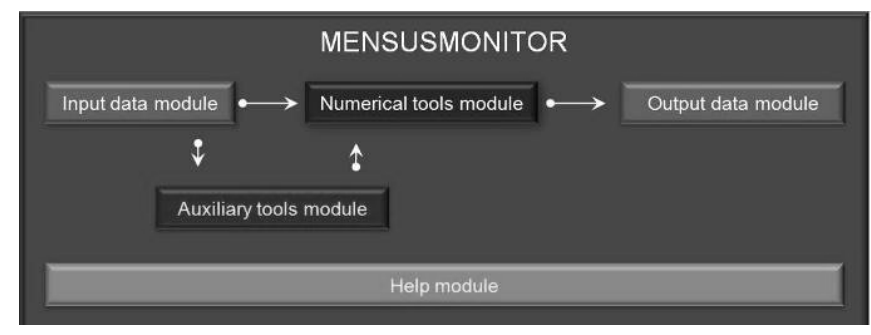

Figure 1. Functioning structure of MENSUSMONITOR.

\section{4 "MENSUS_TRAFFIC" - EVENTS DETECTION ALGORITHM}

\subsection{Problem formulation}

As it was referred, some of the actual monitoring systems used in civil infrastructures allow high sampling rates. Based in those databases, typically fed with readings acquired above a $5 \mathrm{~Hz}$ frequency, it is possible to evaluate some indicators related with the traffic that passes over the monitored structure, namely: (i) daily traffic volume; (ii) velocities and moving directions; (iii) load levels due to the traffic events detected.

\subsection{Methodology and numerical implementation}

The adopted methodology was based in the following five main steps: (i) pre-treatment of the experimental results; (ii) detection of the extreme values; (iii) calculation of the respective velocities and moving directions; (iv) determination of the load levels; (v) plot of histogram results. These five main steps 
embody the "mensus_traffic" tool, which was developed in LabVIEW and C++ and afterwards included in the mainframe of the MENSUSMONITOR.

\subsubsection{Pre-treatment of data}

Considering the database to study, the first step to be performed is to split that database in smaller sets. This procedure is controlled by the user by defining how large those smaller databases are. For each one, a procedure is made to extract only the information related with the traffic events, by subtracting a tendency line and data filtering.

\subsubsection{Extreme values detection}

The pre-treated data is now used to identify the local extreme values. This identification is made by considering a sensibility value for which the search method is initialized (Fig. 2).

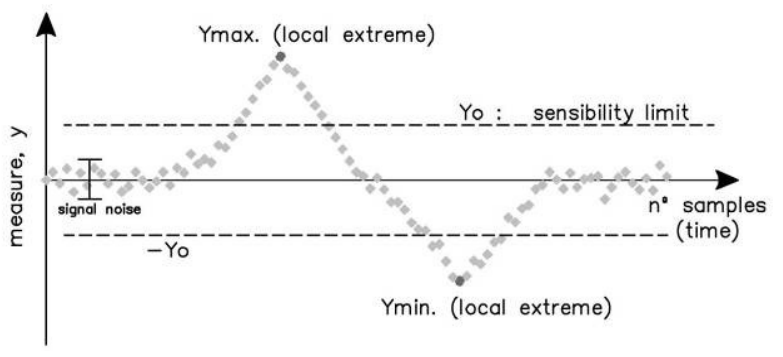

Figure 2. Local extreme values identification.

Therefore, the local extreme values identification of a time series $Y(t, y)$ of ' $n$ ' samples is performed by the following algorithm:

Matrix ' $Y$ '; //time series (ti,yi) with dimension $\mathrm{nx} 2$ Matrix 'Y_sub'; //time series part (ti,yi) with dimension $\mathrm{m}(<\mathrm{n}) \mathrm{x} 2$

Matrix 'Y_ext'; //local extremes

Integer ' $\mathrm{j}$ ' $=0$; //local extreme counter

Double 'sensibility_value'=Yo; //sensibility limit

Double ' $m a x$ ' $=0$; //initial value for the local extreme Double 'sample_rate' $=0.1$; //reading frequency

//--

//cicle over Matrix ' $\mathrm{Y}$ '

For $\mathrm{i}=1$ until $\mathrm{n}$

\{ \}

If abs(yi)>Yo then add (ti,yi) to 'Y_sub' matrix; $1 /$

//cicle over 'Y_sub' Matrix

For $\mathrm{i}=1$ unti $\mathrm{m}(<\mathrm{n})$

\{

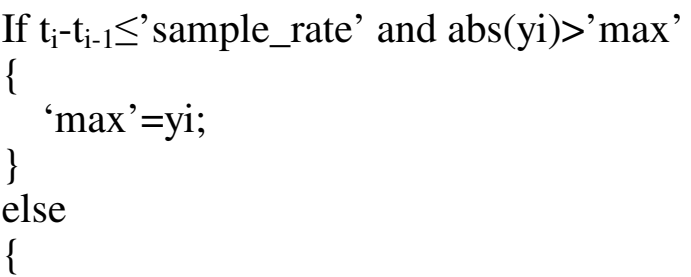

Add 'max' to 'Y_ext' Matrix in index position j;

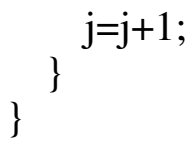

At the end of this calculation step, a matrix $Y\left(t_{i}, y_{i}\right.$ extreme) is created with $j$ extreme values identified. It is relevant to refer the importance of the sensibility value, $Y_{0}$, which makes possible to identify the extreme values and allows the user to obtain different results by setting the desired value for this parameter.

\subsubsection{Velocity calculation and moving direction identification}

With the extreme values identified, the achievement of velocities and moving directions is the next calculation step. For this propose, the user chooses two time series from the time series database related with the traffic events that are intended to be studied, as well as the physical distance between the two sensors from which the data were collected (Fig. 3).

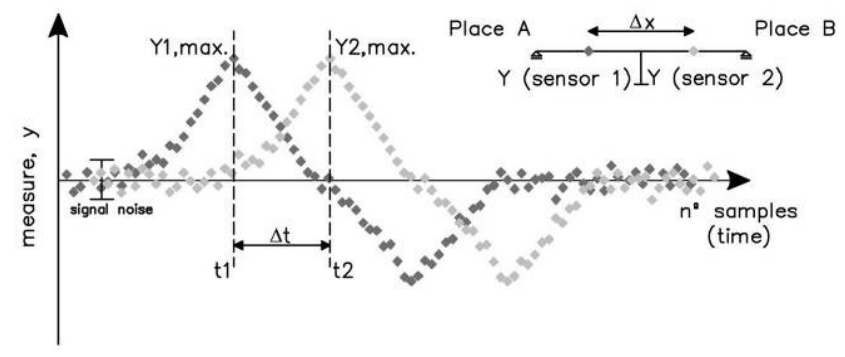

Figure 3. Time interval identification between the local extreme values of two sensors readings.

The calculation procedure pairs the time instants where the extreme values occur. To control the procedure robustness, the user can pre-define: (i) the minimum time interval allowed between two consecutive traffic events for each register; (ii) the maximum time interval allowed for the two extreme values identified by the two sensors for a traffic event. These two parameters can be easily changed as a function of the expected traffic. The velocity calculation is performed by Eq. 1, where the signal result indicates the moving direction.

$$
v=\frac{\Delta x}{\Delta t}=\frac{\Delta x}{t_{2}-t_{1}}
$$

\subsubsection{Determination of the load level}

The effective stress level can be estimated through numerical models and/or load tests performed in the instrumented zone of the structure. With this information a correlation can be established between the vehicles weight and the identified extreme values through a ' $\mathrm{k}$ ' factor (Eq. 2). With this information a matrix $\left(\mathrm{t}_{\mathrm{i}}, \mathrm{F}_{\mathrm{i}}\right)$ can be computed based in the extreme values matrix $\mathrm{Y}\left(\mathrm{t}_{\mathrm{i}}, \mathrm{y}_{\mathrm{i}}\right.$ extreme $)$. 
$F_{i}($ ton $)=k \cdot y_{i, \text { extreme }}$

\subsubsection{Histogram results}

After all described calculation procedures had been performed, "mensus_traffic" allow the results visualization through plots of sets of time series and histograms. Table 1 resumes the plots types considered, with a description of the information contents and axis labels units.

Table 1. Histogram results.

\begin{tabular}{lcc}
\hline Information content & X-Axis & Y-Axis \\
\hline Traffic volume & Time & occurrences counter \\
Weight spectrum & Weight & occurrences counter \\
Moving direction & Time & occurrences counter \\
Velocities spectrum & Velocity & occurrences counter \\
\hline
\end{tabular}

\section{CASE STUDY}

Two bridges equipped with remote and automatic monitoring systems are herein used as case studies to validate the "mensus_traffic" tool. The Pinhão Bridge and Lezíria Bridge are two distinctive bridges in what concerns the structural solution, age and location. It is intended to verify if the "mensus_traffic" tool catches significant differences between the results from these two structures related to traffic volume, crossing velocities and vehicles weights.

\subsection{Pinhão Bridge}

The first case study to be presented as an example of the developed application exploits the results collected by the monitoring system applied to the Pinhão Bridge. This structure crosses the Douro river and is a crucial link of the road network within the vineyard region where is produced the world famous Porto wine (Fig. 4). After the tragic collapse of an older bridge crossing the same river in the year of 2001, the Portuguese national road administration decided to engage a thorough inspection of the structure together with a viability study which led to its strengthening and rehabilitation.

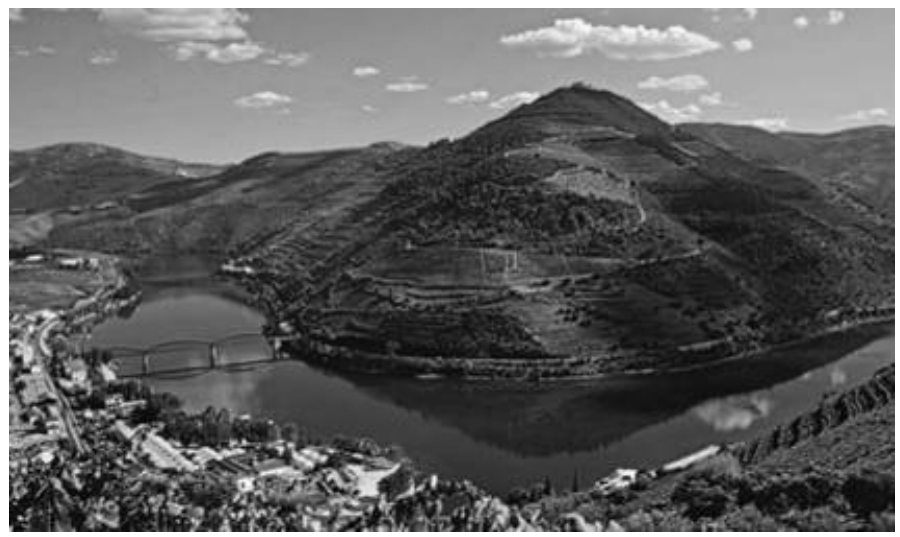

Figure 4. Landscape of the region surrounding Pinhão Bridge.
The Pinhão Bridge comprises three main metallic spans, simply supported, $68.95 \mathrm{~m}$ long, and a short span in the south access. The traffic crosses alternately the bridge in each direction since the road only presents a single lane along its deck. The permanent electric observation system installed in this bridge is constituted by a sensing network of 32 strain gages, 8 temperature sensors, 6 displacement transducers and 2 tiltmeters. The 2 acquisition units have the ability of scanning the sensors signals with a maximum frequency of $100 \mathrm{~Hz}$, well suited for recording the structure dynamic response. Nevertheless, for the structure long-term monitoring the data are acquired by default with a sampling rate of $10 \mathrm{~Hz}$. In (Costa et al., 2009) a more detailed description of the bridge and its monitoring system can be found.

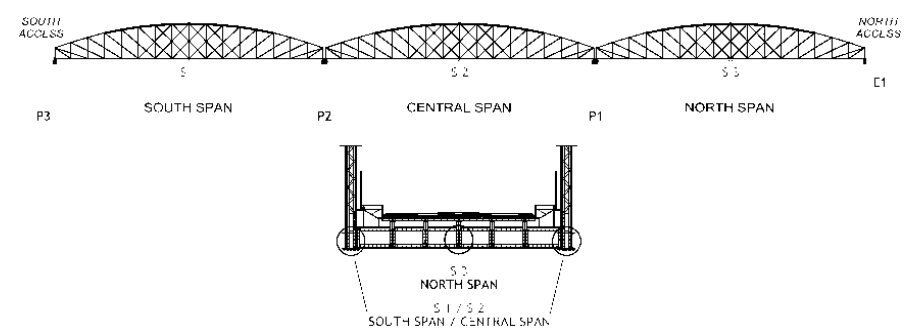

Figure 5. Elevation and mid span cross section of Pinhão Bridge with the location of some instrumented sections.

In order to extract the traffic data three time series collected by as much strain sensors, and spanning a 24 hours observation period, are utilized. The first record concerns the deformation measured by a sensor located at the lower flange of the mid span transverse beam placed in the north span, identified in Figure 5 as section S 3. The data collected with this gage are used in this example for accomplishing the counting of traffic events that crosses the bridge. The reason why this sensor was selected with the purpose of getting this information is related with the fact that among all sensors this one presents the highest sensitivity for the same passing load on the bridge. Figure 6 illustrates a representative time series of the signal acquired with this sensor for a sampling rate of $10 \mathrm{~Hz}$. The graph results from the decomposition of the original daily record in fractions of $50 \mathrm{~min}$ utes, in which the effects induced in the structure response by both, the environmental factors and the dynamic behavior, are purged by using the already existing tools within MENSUSMONITOR.

After the creation of the matrix containing the local maximums and corresponding instants, it is possible to characterize the traffic that crosses the structure, taking into account the sensor sensitivity in relation to the applied load. For this purpose data collected through a load test performed on the bridge are used, which led to a sensitivity factor near $2.10 \mu \varepsilon /$ ton (Costa et al., 2008). Figure 7 presents the counting of vehicles that crossed the bridge deck 
during the observation period, rated in three different classes: i) higher than 12 tons (heavy weight vehicle); ii) between 7 and 12 tons (medium-to-heavy weight vehicle); iii) above 2 tons but less than 7 tons (medium weight vehicle). The combined effect of sensor sensitivity and readings signal to noise ratio has made impossible the identification of automobiles (light weight vehicles) since their average weight is around 2 tons.

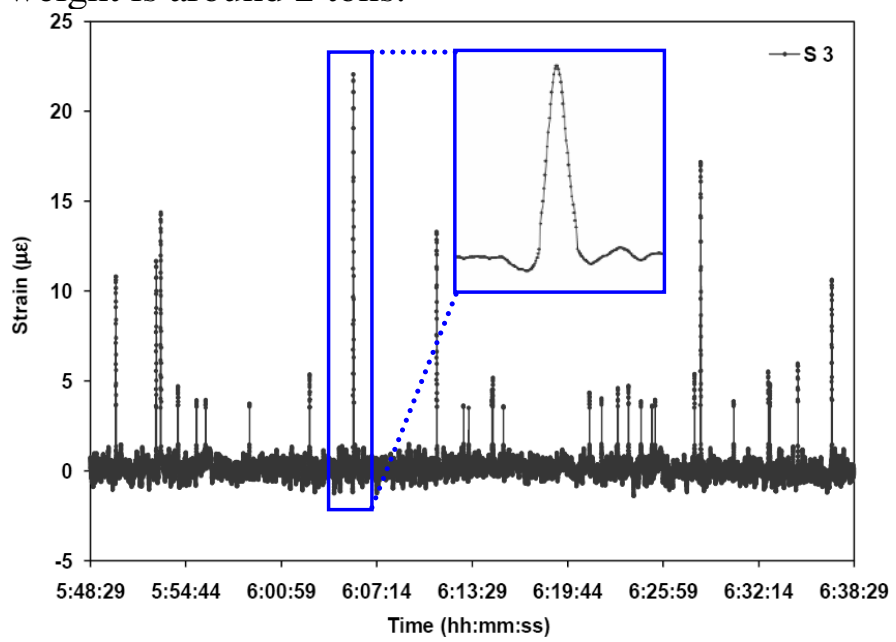

Figure 6. Continuous record of strains in section $S 3(f=10 \mathrm{~Hz})$.

Observing this diagram one can clearly perceive the absence of vehicles weighing more than 2 tons crossing the bridge during the dawn, unlike the periods between $10 \mathrm{~h}-12 \mathrm{~h}$ and $16 \mathrm{~h}-18 \mathrm{~h}$ where the traffic has its maximum intensity. Additionally, the vast majority of events are due to vehicles weighing between 2 and 7 tons.

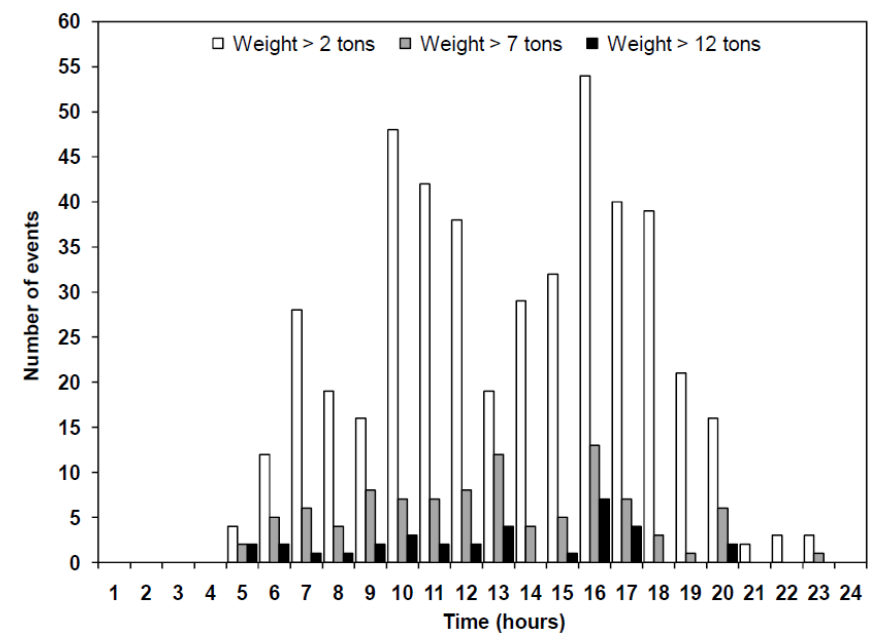

Figure 7. Traffic evolution during the observed period.

The data can also be presented in the form of a traffic spectrum as a function of vehicles weight. Figure 7 depicts this diagram for the observation period. The graph reveals that one third of the vehicles of this counting have a weight above 4.5 tons and only 10 vehicles weighing more than 24.5 tons crossed the bridge during whole day, in correspondence to as much passing tank trucks. More, the his- togram trend presents a decreasing evolution of exponential type.

For accomplishing an analysis to the vehicles velocities of the traffic, as well as to their moving directions, the average strain readings from the mid span lower chords in south and central spans were used. These sections are identified in Figure 5 as $\mathrm{S} 1$ and $\mathrm{S} 2$.

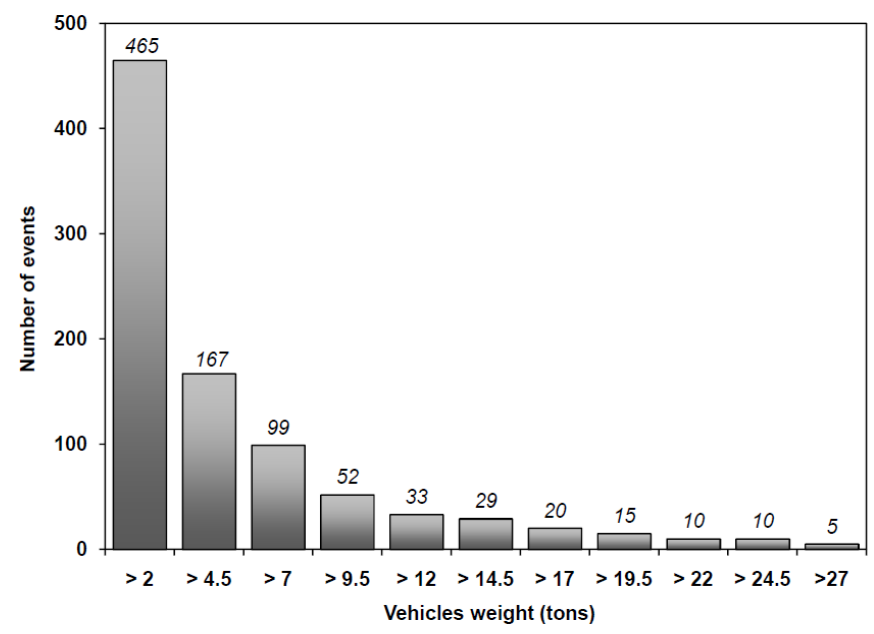

Figure 8. Vehicles crossings frequency for several weight classes (24 hours period).

The selection of theses sensors to supply the time series of interest is due to the following reasons. First one is related to the structure characteristics and its behavior. Since both spans have the same mechanical and geometric features, in principle, the effect induced by crossing vehicles in homologous sections, for identical relative load positions in both spans, should be very similar. The second reason is due to the monitoring system itself, since a single interrogation unit allows the synchronized acquisition of all sensors signals applied to both spans.

Figure 9 presents the moving directions of vehicles weighing more than 9.5 tons, during the 24 hours observation period. The average speed of this class of vehicles is $37.6 \mathrm{~km} / \mathrm{h}$.

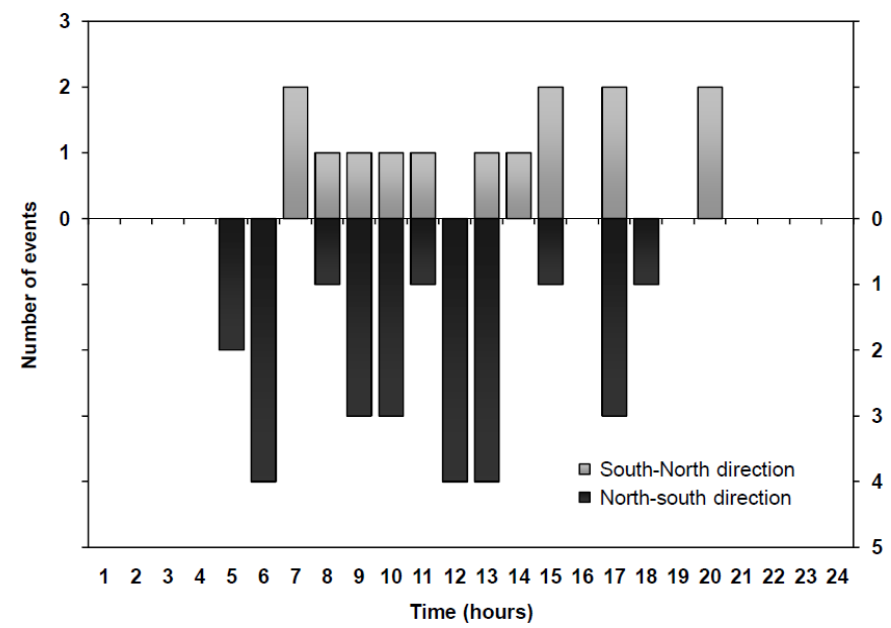

Figure 9. Histogram of moving directions for vehicles weighing more than 9.5 tons. 
The diagram reveals a clear trend towards the north-south moving direction, in a relation of 4 vehicles for each one travelling in the opposite direction.

Finally in Figure 10 a velocity spectrum for the same weight class of vehicles is shown. The distribution of vehicles is presented in a histogram form which can be well fitted to a normal distribution curve.

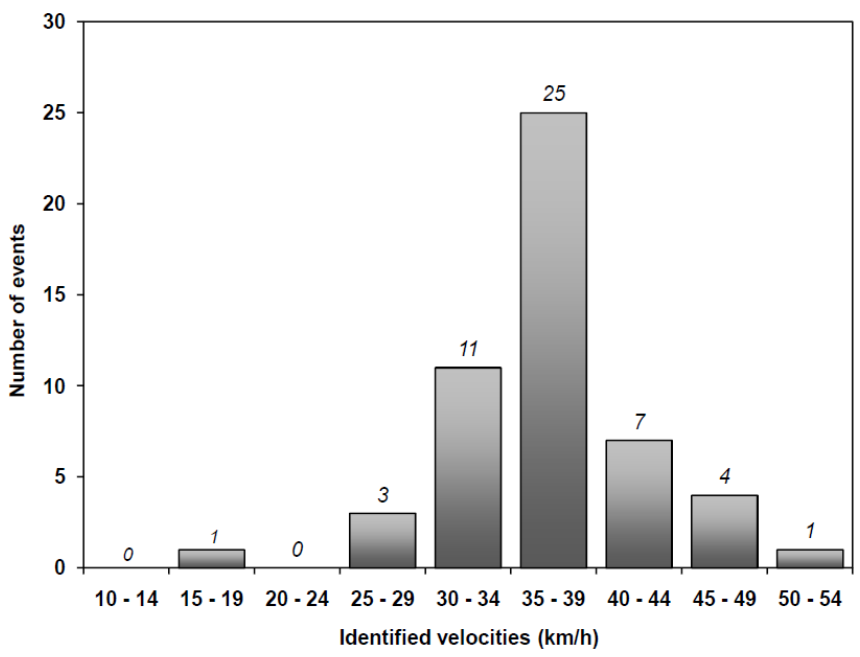

Figure 10. Velocities distribution of vehicles weighing more than 9.5 tons.

\subsection{Lezíria Bridge}

The Lezíria Bridge is inserted in the A10 - Highway Bucelas / Carregado (A1) / IC3 (A13). With a total length of $39.9 \mathrm{~km}$, this highway is an outside bound to the Lisbon Metropolitan Area. It benefits to those who wishing to travel to or from Alentejo or the Algarve (A2 highway) and Spain (A6 highway), without crossing the Portugal capital - Lisbon. In addition, this new bridge will improve the accessibility between Vila Franca de Xira and the Samora Correia/Benavente locations leading to a substantial traffic relief in the national roads EN10 and EN118 (Oliveira, 2008). The $11,670 \mathrm{~m}$ total length of the Lezíria Bridge is materialized by three substructures: (i) the north approach viaduct with $1700 \mathrm{~m}$ of length; (ii) the main bridge substructure, crossing the Tagus river, with a total length of $970 \mathrm{~m}$; (iii) and the largest substructure, the south approach viaduct, with a total length of $9160 \mathrm{~m}$ (Fig. 11). The main bridge structure is formed by 8 spans and 7 pillars supported by pile caps over the river bed. The spans length is $130 \mathrm{~m}$ except for the end spans, which is $95 \mathrm{~m}$, and for two of the mid spans whose length differ in $5 \mathrm{~m}$ due to a change in a pillar implementation that led to spans with $125 \mathrm{~m}$ and $135 \mathrm{~m}$ of length. The bridge deck is materialized by a box girder of variable inertia with about $10 \mathrm{~m}$ of width and heights varying between $4 \mathrm{~m}$ and $8 \mathrm{~m}$. The box girder core construction was made by segmental construction using a movable scaffolding while the side consoles were subsequently constructed sustained by a differ- ent movable scaffolding and metallic struts fixed in the bottom slab of the box girder (Fig. 11). The concrete pillars are formed by four walls with constant thickness and variable width and are supported by pile caps ( 8 piles in general and 10 in the two pile caps bounding the navigation channel).

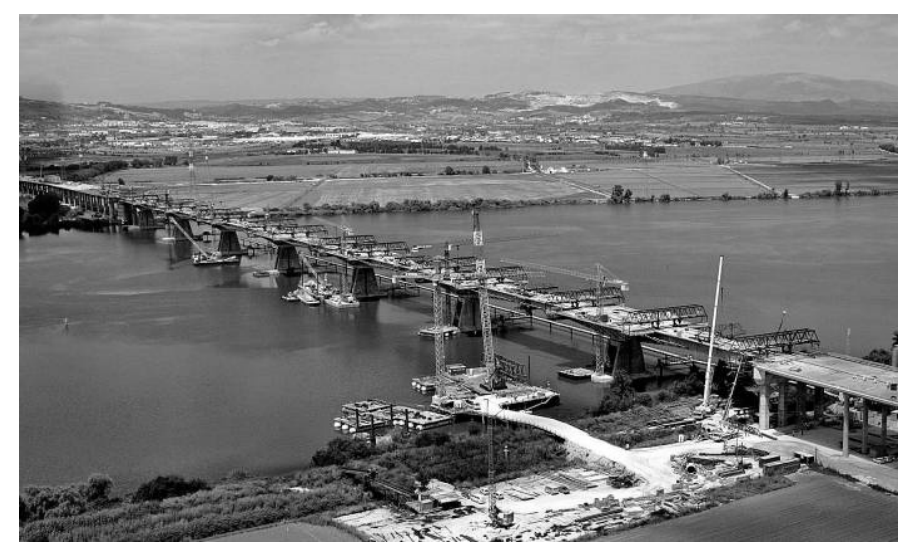

Figure 11. Lezíria Bridge: construction stage in May 2007.

The Lezíria Bridge is equipped with an integrated monitoring system targeting the management and surveillance of the structure. Several cross sections are instrumented with embedded and external sensors, and they are distributed along the bridge length crossing the three sub-structures (viaducts and main bridge). The installed sensors measure a set of quantities, since static, dynamic and durability parameters (Figueiras, 2007). For the "mensus_traffic" propose the records obtained by two optical strain gauges are used. The observation period refers to $24 \mathrm{~h}$ of continuous observation between 14 and 15 May of 2009, with a sampling rate of $50 \mathrm{~Hz}$. The two strain gauges are located in two cross sections, spaced of $130 \mathrm{~m}$, sections $\mathrm{S}-\mathrm{A}$ and $\mathrm{S}-\mathrm{B}$, at the mid span between the pillars pairs $\mathrm{P} 1 / \mathrm{P} 2$ and $\mathrm{P} 2 / \mathrm{P} 3$, respectively. In those two sections, the strain gauges are positioned at the bottom layer of the box girder cross section, "SA_SG_Inferior" and "S-B_SG_Inferior", respectively (Figure 12).

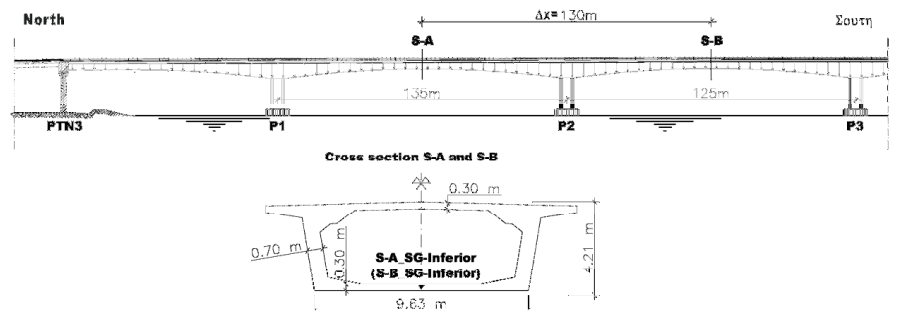

Figure 12. Strain-gauges location used for "mensus_traffic".

From the referred observation period, Figure 13 shows a time window of $4 \mathrm{~m} 40 \mathrm{~s}$ were it is presented the local extremes detection from the data of the strain gauges "S-A_SG_Inf" and "S-B_SG_Inf" by the algorithm "mensus_trafiic" (small circles). Based in the identified local extremes and in the load tests performed during the bridge construction, where a 
relation of 9.35 ton $/ \mu \varepsilon$ was established for the bottom layer deformation of the box girder at mid span between pillars P1 and P2 (section S-A), a weight spectrum was obtained. Figure 14 illustrates the number of occurrences for different weight classes.

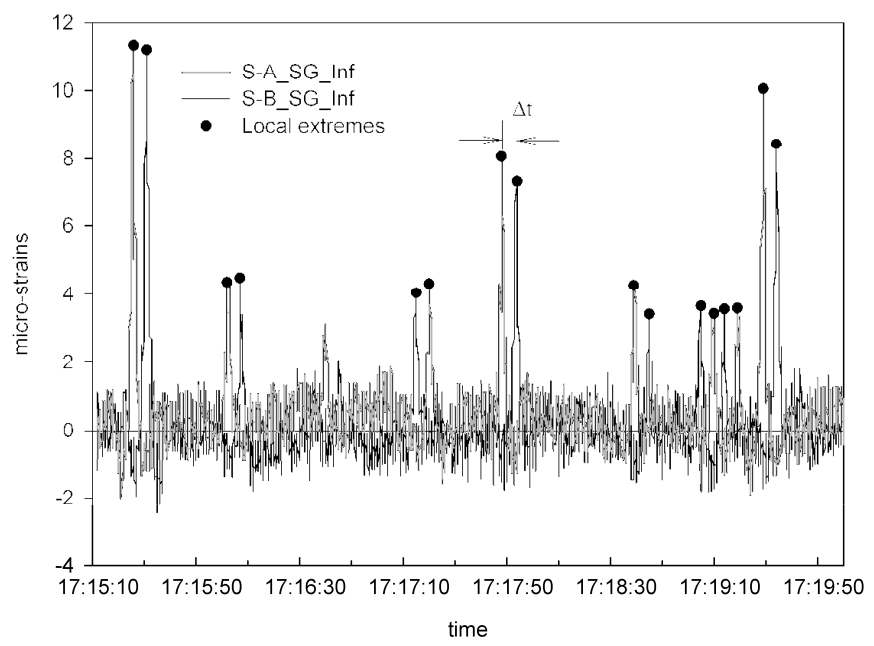

Figure 13. Local extremes detected by "mensus_traffic" from the data of strain gauges "S-A_SG_Inf" and "S-B_SG_Inf".

Due to the noise amplitude, the sensibility parameter, $\mathrm{Y}_{0}$, was set on $3 \mu \varepsilon$, having as consequence the possibility of detecting only traffic events above 28ton. In these conditions, during the observation period a total of 581 traffic events with weight above 28 ton were detected, and from those $3 \%$ surpass the 100ton corresponding perhaps to special transportations.

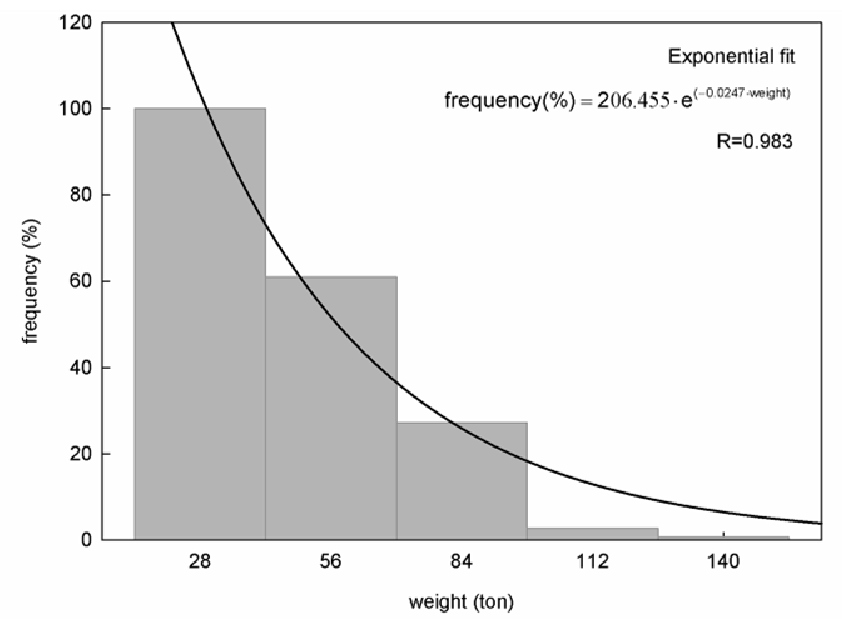

Figure 14. Traffic events weight spectrum.

Considering the local extremes identified for both strain gauges: "S-A_SG_Inf" and "S-B_SG_Inf", the velocities spectrum is calculated from Eq. 1. Figure 15 presents the obtained results, as well as the normal distribution fitting. The average speed from that distribution is about $89 \mathrm{~km} / \mathrm{h}$, which is in accordance with the speed limit established for the heavy traffic in Portugal, whose value is $90 \mathrm{~km} / \mathrm{h}$.

Finally, from the set of results obtained for the velocities calculations, the signal (positive or nega- tive) allowed to know the traffic direction. Figure 16 shows that heavy traffic heading south is the most predominant, given that among the 24 observed hours, 13 of them reveal a more intensive traffic in that direction. Only 7 hours of record present a more intense traffic in the north direction, mainly occurring during the afternoon between $17 \mathrm{~h}$ and $21 \mathrm{~h}$.

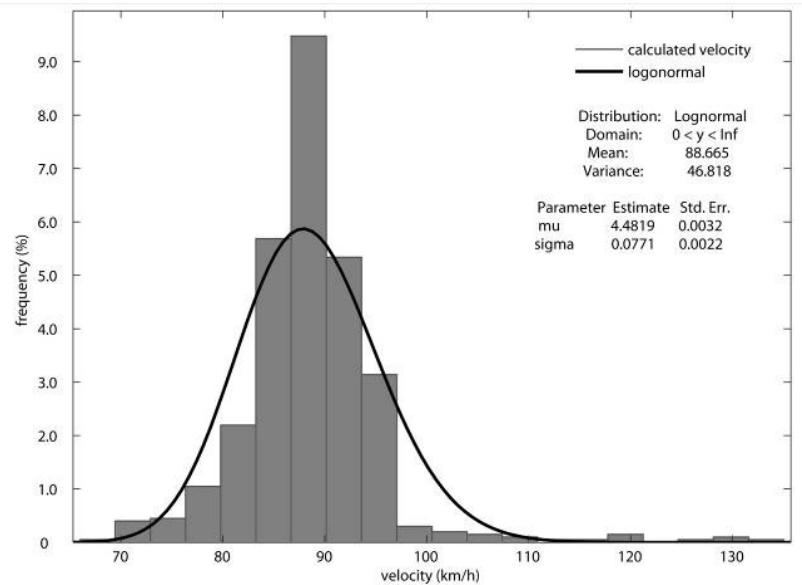

Figure 15. Traffic events velocities distribution.

The representation of the accumulated traffic events confirms the predominance of the traffic heading south. It is also interpreted that heavy traffic intensity diminishes significantly during the night (between 9 p.m. and 3 a.m).

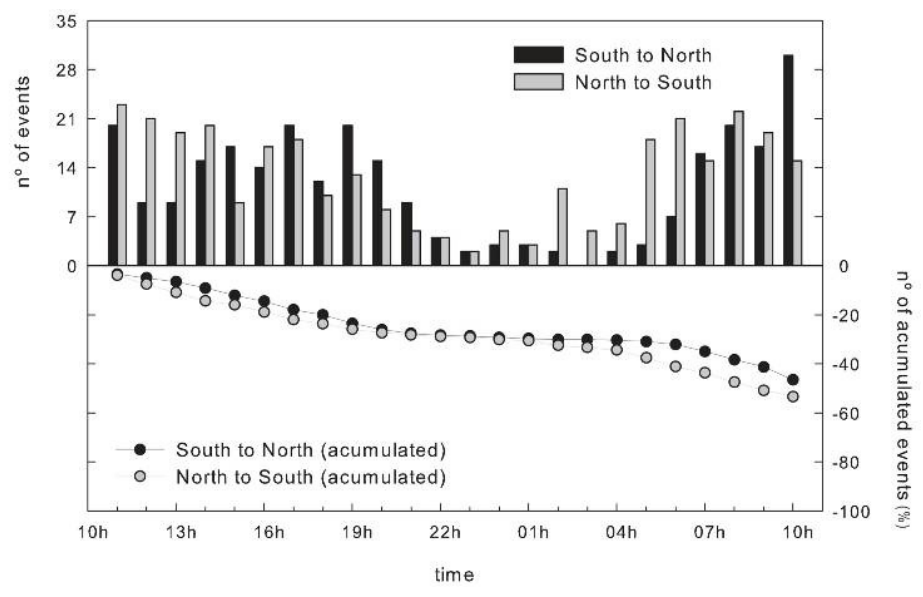

Figure 16. Traffic events direction.

\subsection{Results comparison and discussion}

Comparing the results from both bridges a clear conclusion emerges, which is the ability of instrumented metallic structures to sense smaller loads. Even though it is not an unexpected outcome since they are more flexible, and therefore prone to experience higher deformations, it sets some limitations in the characterization of an important range of traffic for concrete bridges.

Nevertheless one should have in mind the fact that if these results are intended to be used for structural safety analysis of this bridge or similar, instead of transportation purposes, they cover just the essen- 
tial data since the crossing events which led to them are the ones that induce meaningful response of the structure. As a result the algorithm herein presented can extract the proper data for the characterization of live loads passing through the structure, thus may be used in probabilistic studies such as reliability analysis.

Other conclusion that can be drawn is the type and level of heavy traffic. While in Pinhão Bridge no more than 5 load events weighing at least 25 tons cross the structure deck for Lezíria Bridge that number is much higher, setting a ratio of 1 to 10 . This is justified by the fact that one is inserted in a national road with only one lane while the other is located in a highway and presents 6 lanes of traffic, 3 for each direction.

In the case of Lezíria Bridge, during the observation period a set of videos were performed to visualize in fact the traffic passing over the bridge. The number of events detected by the algorithm is in accordance with the video records, except a few cases observed were two or more vehicles cross simultaneous and blinds the algorithm procedure.

Finally, an important observation must be made. If a convoy of vehicles crosses the bridge the algorithm considers it as one single vehicle whose weight has an effect equal to the actual distributed load. The algorithm detects structural effects (which is what it maters for a structural analysis) and not the vehicles counting.

\section{CONCLUSIONS}

In what it concerns to the numerical tool here presented, "mensus_traffic", the considered case studies demonstrated the potential that this tool has in the traffic parameters identification and quantification. Based in time series with a sampling rate typically greater than $5 \mathrm{~Hz}$, the results obtained are relevant and a superior knowledge in the traffic characterization is achieved. The obtained results can be relevant in decision processes related with the structures management and surveillance, namely in the adoption of restrictive actions to the traffic, viability studies and/or rehabilitation of structures.

In the perspective of the MENSUSMONITOR application, the attachment of "mensus_traffic" to this application has benefited of the numerical tools already implemented, namely: (i) the input data module to open the data files originated by the acquisition systems and; (ii) the auxiliary tools module for the data pre-treatment. This facts ground the gain that is achieved by an application that is developed in a modular fashion, allowing the attachment of new functionalities with less effort by taking the application potentialities already implemented.

Finally, this type of tools may reveal to be very useful in understanding the suitability of the Euro- pean codes of actions on road and railway bridges to the Portuguese reality since they were developed mostly on a Central European traffic basis, which can be very different for a country in the fringe of this continent.

\section{ACKNOWLEDGEMENTS}

The first author expresses thankfulness to the Portuguese Foundation for Science and Technology for the funding of his doctoral studies.

\section{REFERENCES}

Beeby, A. W. 2005. Designers' guide to EN 1992-1-1 and EN 1992-1-2 :Eurocode 2: design of concrete structures : general rules and rules for buildings and structural fire design. London: Thomas Telford. (Designers' guides to the Eurocodes).

Beyon, J. Y. 2001. LabVIEW programming data acquisition and analysis. Upper Saddle River, NJ: Prentice Hall PTR.

Costa, B.J.A., Félix, C. \& Figueiras, J.A.. 2009. Design and installation of an electric based monitoring system applied to a centenary metallic bridge. ASCP'09 - $1^{\circ}$ Congresso de Segurança e Conservação de Pontes, Lisbon (in portuguese).

Costa, B.J.A., Faria, R. \& Figueiras, J.A.. 2008. Instrumentation and observation of the Pinhão Bridge behavior during the load tests (Thecnical report), LABEST-FEUP, Porto (in portuguese).

Figueiras, J. et al. 2007. Construção da Travessia do Tejo no Carregado Sublanço A1/Benavente, da A10 Auto-Estrada Bucelas/Carregado/IC3: Projecto Executivo Monitorização Estrutural e de Durabilidade 0 - Apresentação. LABEST, Faculdade de Engenharia da Universidade do Porto. (in Portuguese)

Karoumi R., Wiberg, J. \& Liljencrantz, A. 2005. Monitoring traffic loads and dynamic effects using an instrumented railway bridge. Engineering Structures 27(12): 1813-1819.

Oliveira, C. B. 2006. "New crossing of the Tagus river from Carregado to Lezíria through A10." Ingenium, $\mathrm{n}^{\circ}$ 95. (in Portuguese)

Sousa, H., et al. 2008. MENSUSMONITOR - Tool for the treatment and interpretation of experimental results in Civil Engineering. CCC 2008 - Challenges for Civil Construction. Porto: FEUP.

Sousa, H. et al. 2008. MENSUSMONITOR - Ferramenta de cálculo para tratamento e interpretação de resultados experimentais em Engenharia Civil. BE 2008 - Encontro Nacional de Betão Estrutural 2008, Guimarães: Congress center Vila Flor. (in portuguese) 